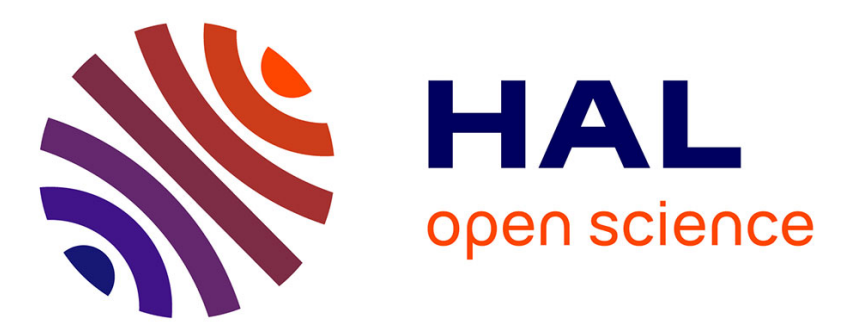

\title{
Synchrotron X-ray transmission topography of vapour grown $\alpha$-HgI2 crystals
}

F. Remy, J. Gastaldi, G. Le Lay, A. Rossberg, M. Piechotka, G. Wetzel, E. Kaldis

\section{- To cite this version:}

F. Remy, J. Gastaldi, G. Le Lay, A. Rossberg, M. Piechotka, et al.. Synchrotron X-ray transmission topography of vapour grown $\alpha$-HgI2 crystals. Journal de Physique IV Proceedings, 1994, 04 (C9), pp.C9-203-C9-207. 10.1051/jp4:1994936 . jpa-00253497

\section{HAL Id: jpa-00253497 https://hal.science/jpa-00253497}

Submitted on 1 Jan 1994

HAL is a multi-disciplinary open access archive for the deposit and dissemination of scientific research documents, whether they are published or not. The documents may come from teaching and research institutions in France or abroad, or from public or private research centers.
L'archive ouverte pluridisciplinaire HAL, est destinée au dépôt et à la diffusion de documents scientifiques de niveau recherche, publiés ou non, émanant des établissements d'enseignement et de recherche français ou étrangers, des laboratoires publics ou privés. 


\title{
Synchrotron X-ray transmission topography of vapour grown $\alpha-\mathrm{HgI}_{2}$ crystals
}

\author{
F. Remy, J. Gastaldi, G. Le Lay, A. Rossberg*, M. Piechotka*, G. Wetzel* and E. Kaldis* \\ CRMC2/CNRS, Campus de Luminy, Case 913, 13288 Marseille cedex 09, France \\ * Laboratorium für Festkörperphysik, ETH Hönggerberg, 8093 Zurich, Switzerland
}

\begin{abstract}
Résumé.- On a étudié, par Topographie aux Rayons X Synchrotron en transmission, la perfection cristalline de monocristaux d'iodure mercurique $\mathrm{HgI}_{2}-\alpha$, produits par transport en phase vapeur, dans une région présentant des striations. La géométrie des striations a pu être précisée grâce à l'étude de plusieurs lames cristallines taillées sous différents angles; de plus l'enregistrement de topographies au cours de l'amincissement progressif des lames cristallines nous a donné un aperçu du champ de contraintes à longue distance associé aux striations et nous a permis d'y résoudre des défauts individuels, et de ce fait de proposer une hypothèse quant à leur origine.
\end{abstract}

\begin{abstract}
Results of a study by Synchrotron X-ray Topography in transmission of the perfection of vapour grown single crystals of mercuric iodide, $\alpha-\mathrm{HgI}_{2}$, in regions containing striations are presented. The geometry of the striations was precisely defined because we could examine several samples cut along different orientations; moreover topographs recorded at different stages of crystal thinning allowed us to have an insight of the long range strain field associated with the striations and to resolve the defects inside them. A possible origin of these defects is discussed.
\end{abstract}

\section{INTRODUCTION}

High-quality, large mercuric iodide crystals are needed for the purpose of fabricating X-ray and gammaray radiation detectors operating at room temperature [1]. At present the crystals are grown exclusively by the Physical Vapour Transport (PVT) method, from source material purified by repeted sublimation. To date the yield of spectroscopy-grade detector is still low, due to a high concentration of defects [2]. Most of the structural defects originate during the growth. One of them - striations - seem to appear in all large $\mathrm{HgI}_{2}$ crystals, but in varying density and geometry depending on the growth method applied. They have at first been observed by Schieber et al.[3] in a crystal grown by the Temperature Oscillating Method (TOM). However, they appear also in crystals grown by the static PVT method. Formation of some striations has been correlated to the temperature decrements of the cold finger by $0.1^{\circ} \mathrm{C}$ steps needed to maintain a constant growth rate during growth $[4,5]$.

Our previous investigations demonstrated that relevant information on growth defects in $\alpha-\mathrm{Hgl} 2$ crystals can be collected by recording Synchrotron X-ray topographs, in transmission, from lamellae carefully cut from bulky samples $[6,7]$. 
In this paper we report new results, from investigations performed mainly in the striation regions of crystals grown at ETH, Zürich which provide some insight about the crystalline perfection of these regions or of their neighbouring and a 3-dimensional view of the striations.

\section{EXPERIMENT}

$\mathrm{X}$-ray topographic investigations were carried out at the LURE (Orsay) synchrotron X-ray white-beam source of the $1.85 \mathrm{GeV}$ DCI storage ring. The patterns were recorded in transmission (Laue) geometry on nuclear plates (Ilford L4, $50 \mu \mathrm{m}$ ) disposed at $6 \mathrm{~cm}$ from the crystal. As it is usual in topography to rotate the crystalline sample a few degrees off the axis normal to its surface in order to image spots with strong intensities, the exact orientation of each Laue pattern and the indexing of its spots (topographs) was determined afterwards by means of a computer program [8].

The crystal wafers were cut with a cotton thread saw (wetted by a potassium iodide aqueous solution 10-20 wt.\%).

As the mercuric iodide material is a strong X-ray absorber several operations of thinning down each wafer to a few hundred $\mu \mathrm{m}$ in $\mathrm{KI}$ aqueous solution were done until topographs revealed some features, defects, etc. present inside the sample.

\section{RESULTS}

Four wafers $\left(\mathrm{C} 7 / 7, \mathrm{C} 7 / 8, \mathrm{C} 7 / 9\right.$ and $\left.\mathrm{N}^{\circ} 2\right)$ cut from a vapour grown crystal were investigated (see sketch of the crystal on fig. 1a to locate the cuts).The geometry of the striations in the crystal as seen from these topographic observations is presented schematically in fig. $1 \mathrm{~b}$.

The C7/7 lamella was cut along the (100)

plane diagonally through the striated region. On the topographs, horizontal "fine lines" parallel to the [010] direction, intersection of the basal plane (001) with the lamella face (100), are imaged (fig. $2 a)$, as well as vertical bands parallel to the [001] direction. In the thick part of that lamella, the "fine lines" are rather large and dense, the vertical ones are barely visible. After further thinning (fig. $2 b)$, the "fine lines" are finer and less dense in the finer part of this lamella toward a hole ; the vertical bands are much more visible, and depth fringes are seen around the hole.

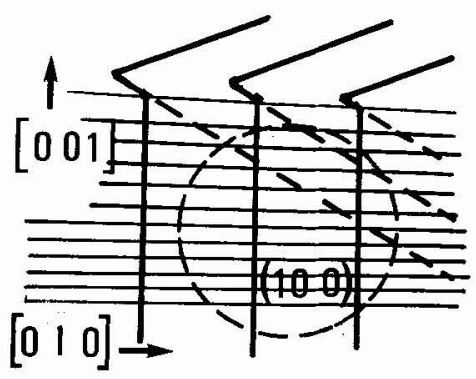

a

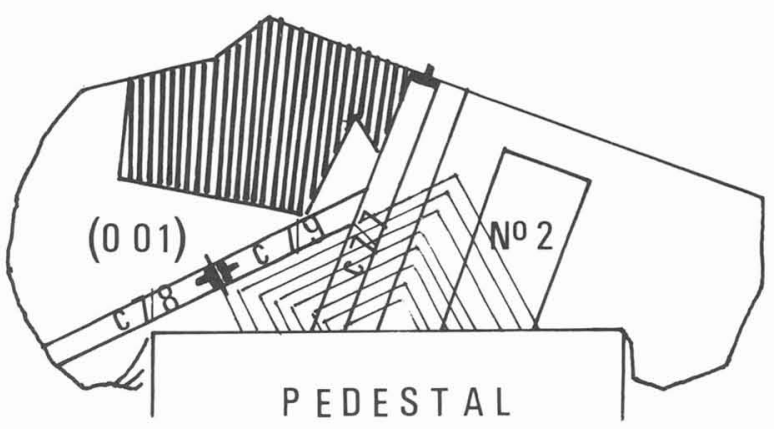

fig.1a : Sketch of the $\mathrm{HgI}_{2}$ crystal, with location of the four wafers investigated by Synchrotron Topography.
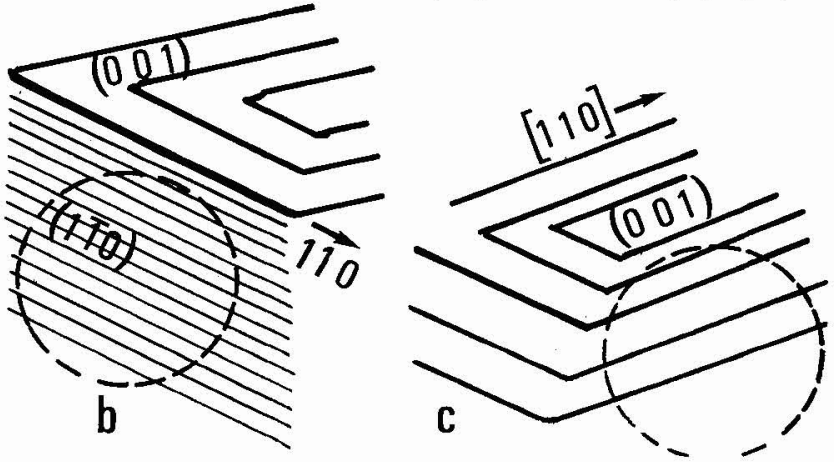

fig. $1 \mathrm{~b}$ : Orientation of the cuts with respect to the striations, as seen from the $\mathrm{C} 7 / 7, \mathrm{C} 7 / 9$ and $\mathrm{N}^{\circ} 2$ lamellae, a) b) and c) respectively. 


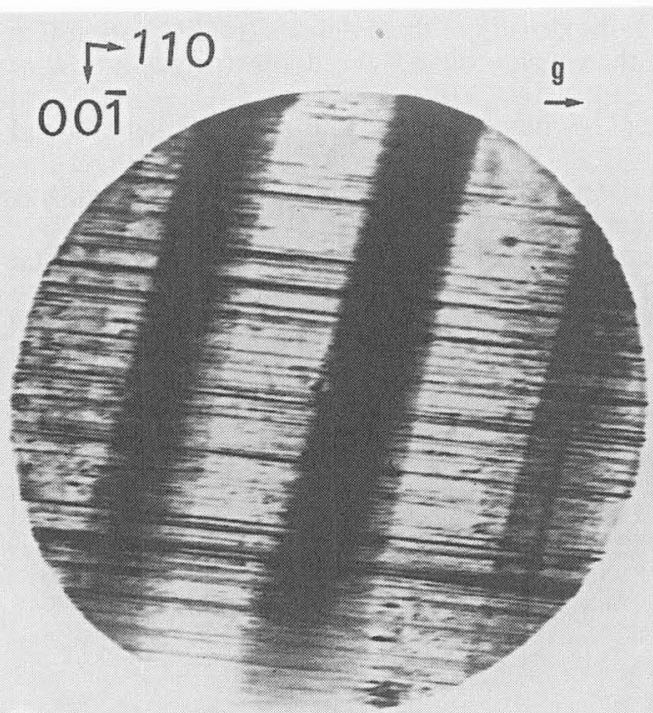

a
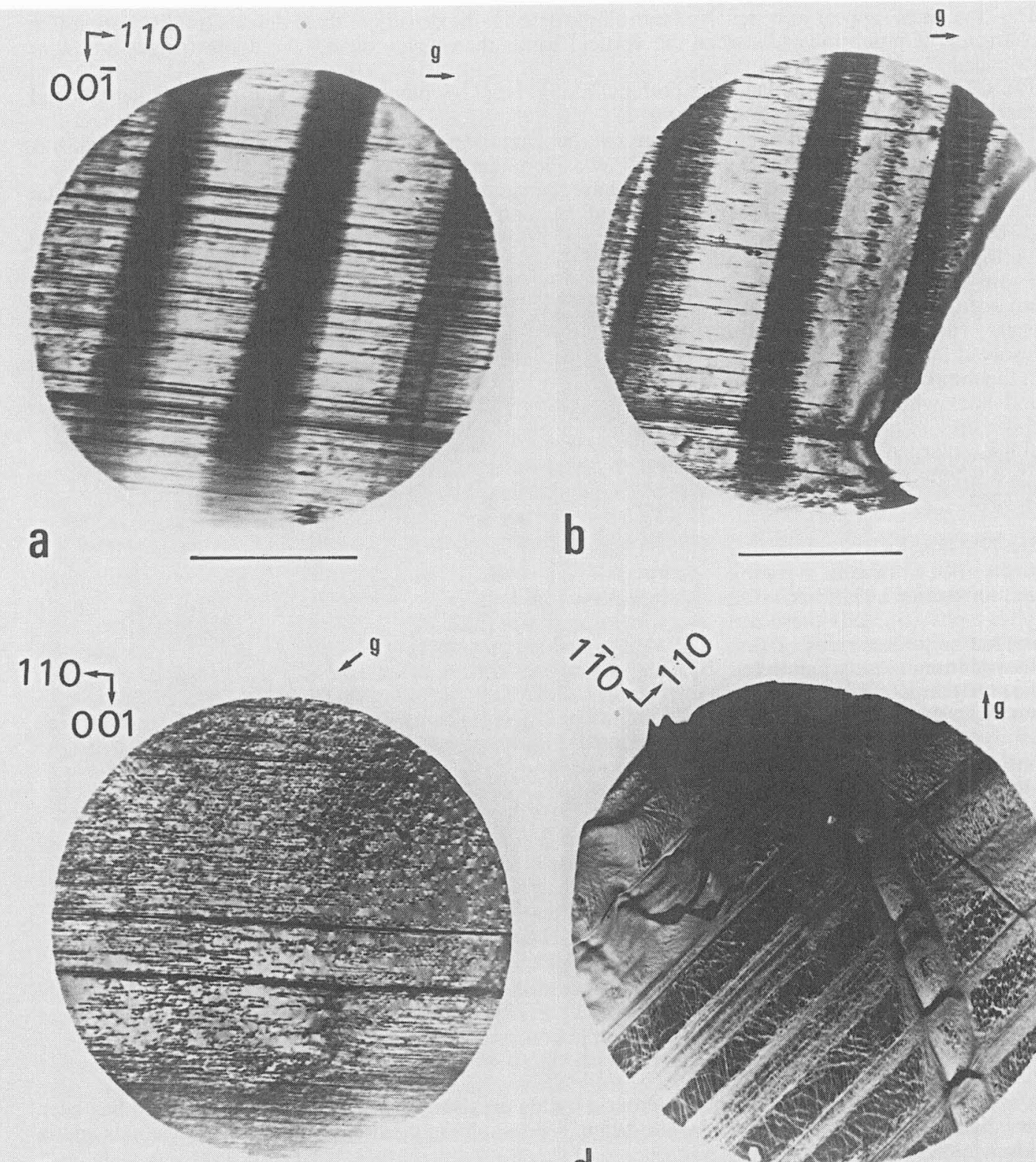

C

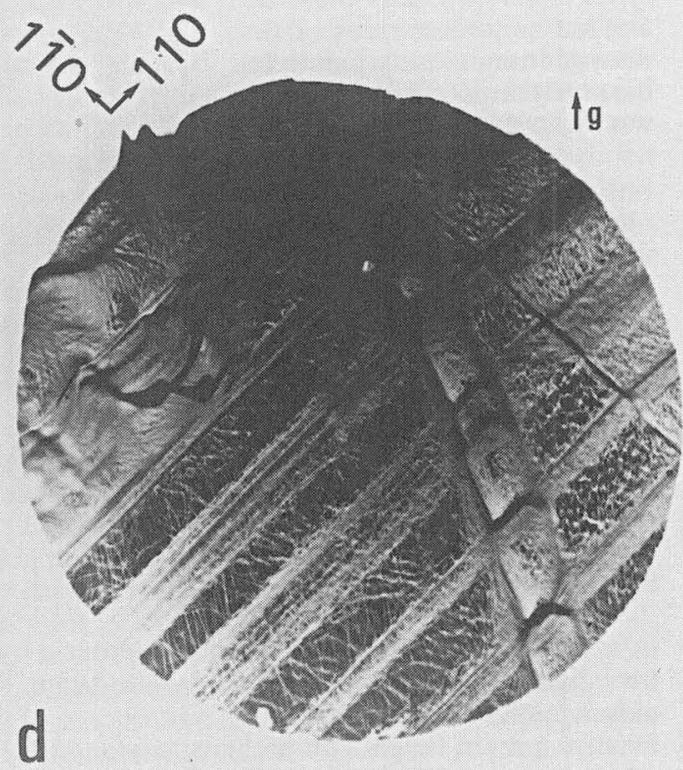

fig. 2: Topographs of the $\mathrm{HgI}_{2}$ crystal from fig. 1, bar scale : $1 \mathrm{~mm}$ (see text);

a) C7/7 lamella, (100) cut, (110) reflection, $\lambda=0.44 \AA$;

b) same lamella as a), after thinning ;

c) C7/9 lamella, (110) cut, (112) reflection, $h=0.40 \AA$;

d) $\mathrm{N}^{\circ} 2$ lamella, (001) cut, (020) reflection, $\mathrm{h}=0.50 \AA$. 
The "fine lines" appear to be resolved into single defects -the density of these defects (of dislocation-like character) is much lower between the vertical bands than inside them - the depth fringes are more extended.

The $C 7 / 8$ and C7/9 lamellae were both cut along the (110) plane, at $45^{\circ}$ from the C7/7 lamella and parallel to the striation direction (see fig. 1):

The C7/8 lamella, located in the outer part overhanging the pedestal and close to the striated region, was founded too much deformed and will not be considered further.

For the C7/9 lamella located in the crystal centre one can see (fig. $2 \mathrm{c}$ ) as general features some horizontal "fine lines" parallel to the [110] direction intersection of the basal plane (001) with the lamella face (110).

On topographs recorded with a $4 \mathrm{~mm}$ diaphragm ,"fine lines" are seen, dense in the thickest parts (up and down) and resolved into individual defects in the thinnest parts (to the right and left) where depth fringes show up. A part of the topograph (enlarged) is presented in fig. 3 where contrast centers can be seen.

The $\mathrm{N}^{\circ} 2$ lamella was cut parallel to the (001) plane in a region including the striations : On topographs (fig. 2d) these are imaged as large stripes of fine lines running closely parallel to the [110] direction, interspersed with more homogeneous dark bands where fewer individual fine white lines (dislocations) run at $45^{\circ}$ from the direction of the stripes. Moreover a large subgrain boundary divide the topograph in two parts.

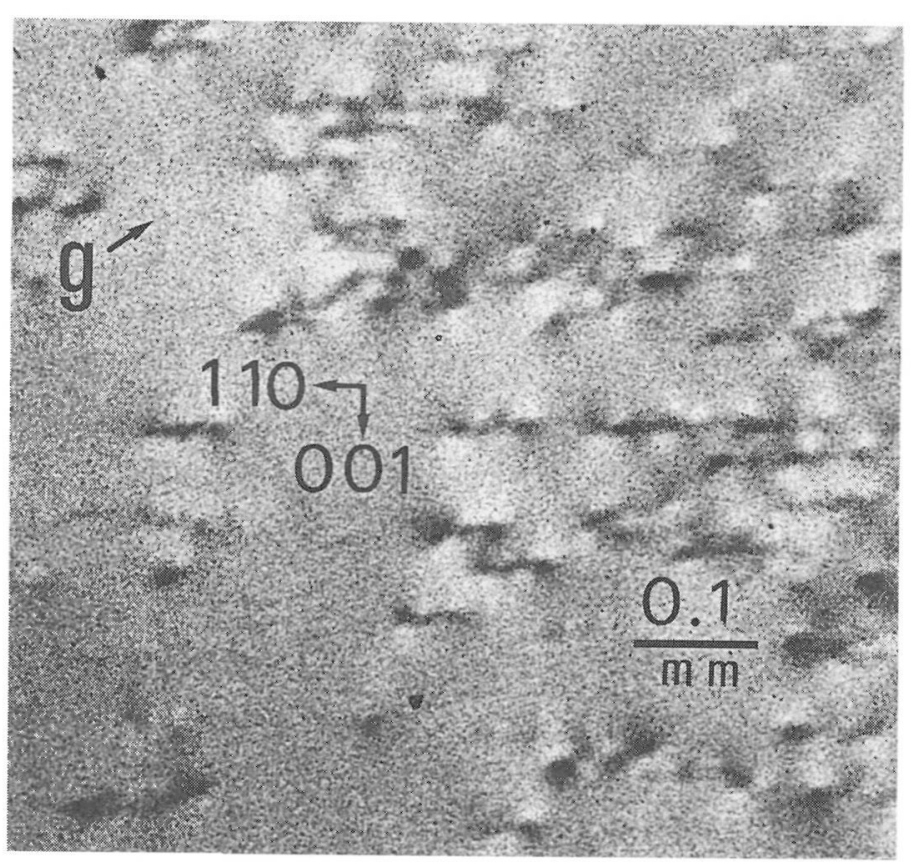

Fig 3. Topograph of the $\mathrm{C} 7 / 9 \mathrm{HgI} 2$ crystal (enlargment) ; (112) reflection, $\lambda=0.40 \AA$

\section{DISCUSSION}

The crystalline perfection of mercuric iodide crystals grown by static PVT method has been investigated by Synchrotron X-ray white-beam Topography in the regions containing striations and in close vicinity to them.

From the more recent comprehensive study of vapour growth $[9,10]$, we know that a) striations are created in planes parallel to the $\{110\}$ faces and do not appear behind the $\{001\}$ ones which remain smooth during growth, b) they cannot be correlated with either intentional or inadvertent temperature variations (measurable down to $\pm 0.010 \mathrm{~K}$ ) in the crystal growth apparatus, c) observations by optical means of the striations during growth indicate that they seem to be related to curved macrosteps on $\{110\}$ growing faces, which propagate along the $<001>$ directions in one or the other sense. Moreover these macrosteps seem to originate either from the $<110>$ edges, intersections of the [110] and $\{001\}$ facets, or even from apices shared by $\{110\},\{001\}$ and $\{\mathrm{h} 01\}$ truncated facets, the sense of travelling of the curved macrosteps being correlated with the appearrance or dissapearance of the latter facets.

Our results indicate that striations are actually seen along the [110] direction. For the first time these striations have been resolved into individual defects by Synchrotron Topography due to the progressive 
thinning of the crystal lamellae performed at Lure. The full characterization of these defects is under study, although it seems that stress centers are present in the crystal, the nature of which is still a much debated question.

Additionaly, we have shown evidence of plastic deformation in the part overhanging the pedestal.

\section{REFERENCES}

[1] Roth S. and Wilig W. R., Appl. Phys. Lett., 18, (1971) p 328.

[2] Bao X. J., Schlesinger T. E., James R. B., Harvey S. J., Cheng A. Y., Garrish V. and Ortale C., Nucl. Instr. and Meth., A 317 (1992) p 194.

[ 3 ] Schieber M., Beinglass I., Dishon G. and Holzer A., in Current Topics in Materials Science, Vol 2, p. 280, E. Kaldis and H. J. Scheel, Eds. (North-Holland, Amsterdam 1977).

[ 4] Zha M., Piechotka M. and Kaldis E., J. Cryst. Growth 115 (1991) 43 - 51.

[ 5 ] Piechotka M. and Kaldis E., ETH, Zurich 1993, ESA Final Report Contract 9990/92/NL/GS.

[6] Remy F., Gastaldi J., Grange G., Jourdan C. and Le Lay G., J. Cryst. Growth 121 (1992) pp 243-246.

[ 7 ] Remy F., Gastaldi J. and Le Lay G., Nucl. Instr. and Meth. in Phys. Res. B 83 (1993) pp 229-234.

[ 8 ] Laugier J. and Filhol A., J. Appl. Cryst. 16 (1983) pp 281.

[ 9 ] Piechotka M. and Kaldis E., ETH, Zurich 1994, ESA Final Report Contract

[10] Piechotka M., J. Cryst. Growth, submitted. 